\title{
Effects of Welding Schedules on Resistance Spot Welding of DP600 Steel
}

\author{
Xiaodong WAN, ${ }^{1 / *}$ Yuanxun WANG ${ }^{1,2)}$ and Peng ZHANG ${ }^{11}$ \\ 1) Department of Mechanics, Huazhong University of Science and Technology, Wuhan 430074, China. \\ 2) Hubei Key Laboratory for Engineering Structural Analysis and Safety Assessment, Luoyu Road 1037, Wuhan 430074, China.
}

(Received on May 21, 2014; accepted on July 7, 2014)

\begin{abstract}
In this study, experiments were made to investigate effects of electrode force, welding current and welding time on weld quality of resistance spot welded DP600 steel. Microstructure, microhardness and mechanical behavior of welded joints were analyzed. Martensite formation was observed in the fusion zone. Heat affected zone softening caused by martensite tempering could be detected. Increasing welding parameters would promote pullout failure occurrence and heat affected zone softening. However, the associated welding defects would have negative effects on weld quality. Welding current influence on weld quality was the most significant among the three selected welding parameters. In addition, penetration rate could probably be used to judge the weld quality.
\end{abstract}

KEY WORDS: dual phase steel; resistance spot welding; weld quality; welding parameters effects.

\section{Introduction}

In order to increase fuel economy, vehicle weight reduction and improved crashworthiness, advanced high strength steels (AHSSs) like dual phase (DP), complex phase (CP), transformation induced plasticity (TRIP) and martensitic (MS) steels are being increasingly used in the automotive industry. DP steel, which contains mostly ferrite and second phase of martensite islands, is more popular with car manufacturers among those steel types. The strength of DP steel is mainly controlled by its volume fraction of martensite. What's more, DP steel shows high initial work-harding rate, low yield to tensile strength ratio and good uniform elongation. ${ }^{1)}$

Resistance spot welding has been the primary welding technique for sheet metal fabrication for decades. Interfacial failure occurs more often in resistance spot welding of DP steel, which makes the weldability of DP steel remaining inconclusive. ${ }^{2,3)}$ Expulsion and other welding defects occur easily during DP steel spot welding, especially in case of strong welding parameters. Investigations have been made for a better understanding of DP steel resistance spot welding.

Ghosh et $\mathrm{al}^{4)}$ investigated the spot weldability of $4 \mathrm{~mm}$ thick DP steel sheet by varying different welding parameters. The optimum welding schedule was established, and martensite tempering was not observed then. Milititsky et $a l .{ }^{5)}$ indicated that DP600 weld hardness showed no hold time sensitivity and welding defects occurrence may be promoted under short hold time welding condition. Ma et $a l^{6)}$

\footnotetext{
* Corresponding author: E-mail: wanxiaodong@hust.edu.cn DOI: http://dx.doi.org/10.2355/isijinternational.54.2375
}

concluded that the load carrying capability of spot welds under interfacial failure was, however, still high enough for DP600 spot welds. Marya et al. ${ }^{7-9)}$ tried to establish a relation between welding parameters and failure modes of spot welded DP steel through experimental study. Long welding time, low welding current, and high electrode force were found to be beneficial for interfacial failure elimination. Weld fracture criterion was developed finally based on empirical equations. Joaquin et al. ${ }^{10)}$ developed several practical techniques to reduce shrinkage voids in resistance spot welding of DP600 steel. Zhang et al. ${ }^{11)}$ improved the weldability of DP steels by adjusting electrode force using servo gun. Zhang et al. ${ }^{12)}$ indicated that a great electrode force is heplful to reduce expulsion occurrence in DP steel resistance spot welding with initial gap. Hernandez et al. ${ }^{13)}$ showed that mechanical properties were improved in dissimilar DP600-DP780 welds, and pullout failure was promoted by heat affected zone (HAZ) softening. Pouranvari et $a l .^{3,14,15)}$ found that failure mode, nugget size, failure location ductility were the main factors controlling mechanical properties of spot welded AHSSs. Welding parameters like electrode force, welding current, welding time and holding time on weld quality were all considered. Nikoosohbat et $a l .{ }^{16)}$ showed that traditional failure criterion was not sufficient in resistance spot welding of DP980 steel any more, and heavy expulsion could reduce load carrying capability. Dancette et $a l .{ }^{17)}$ detected martensite tempering in SCHAZ of DP980, which was responsible for strength reduction and ductility increase of spot welds. Biro et al. ${ }^{18)}$ predicted the transient softening phenomenon in the HAZ of spot welded DP steel using rapid isothermal tempering technique and validated by experiments.

So far, the spot weldability of DP600 is not as clear as tra- 
ditional steels. Comprehensive studies are still need for a better application of DP steel in automotive industry. In this study, two $1.7 \mathrm{~mm}$ thick DP600 steel sheets were used for spot welding process. Effects of different welding parameters on microstructure, microhardness and mechanical properties were investigated experimentally.

\section{Experimental Procedure}

The DP600 steel with $1.7 \mathrm{~mm}$ thickness was used to generate spot welds. An illustration of the specimen size prepared for resistance spot welding is shown in Fig. 1. The chemical composition of this DP600 steel is depicted in Table 1.

A $50 \mathrm{~Hz}$ AC and programmable logic controller (PLC) controlled pneumatic spot welding machine was used for spot welding. Water cooled electrodes were made of copper alloy, and had a flattened face diameter of $6 \mathrm{~mm}$. Electrode force was set as $2.0,2.5,3.5$ and $4.0 \mathrm{kN}$ separately. Welding current varied from $6 \mathrm{kA}$ to $12 \mathrm{kA}$ at intervals of $2 \mathrm{kA}$. Welding time veried between 8 cycles and 17 cycles at intervals of 3 cycles. Each welding condition was repeated for six times, the results adopted were all averaged.

Spot welds were subjected to tensile-shear loads using an universal testing machine in laboratory. Two shims with the

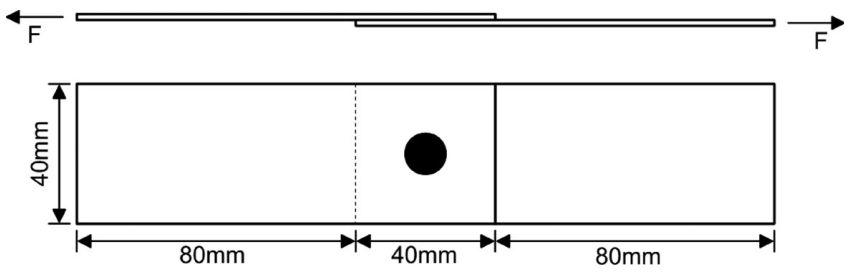

Fig. 1. An illustration of the specimen size prepared for resistance spot welding.

Table 1. The chemical composition of DP600 steel, wt-\%.

\begin{tabular}{ccccccc}
\hline $\mathrm{C}$ & $\mathrm{Si}$ & $\mathrm{Mn}$ & $\mathrm{P}$ & $\mathrm{S}$ & $\mathrm{Al}$ & $\mathrm{N}$ \\
\hline 0.0790 & 1.0000 & 1.5200 & 0.0150 & 0.0049 & 0.0230 & 0.0037 \\
\hline
\end{tabular}

same thickness were used to minimum bending during the tests. Cross-head speed was kept constant at $10 \mathrm{~mm} / \mathrm{min}$. Load-displacement curve and peak load were extracted from the cross-head. Failure energy absorption, which referred to the area under the load-displacement curve up to the peak load, was also recorded. Failure mode was detected from failed samples.

Cross-sectioned specimens were ground, polished and etched with $4 \%$ nital reagent. Optical microscope was then used for examination of microstructure profiles. Nugget size measurement was performed using the AxioVision Software. Vicker's microhardness testing was conducted along the diagonal direction of joints. A indenter with $100 \mathrm{~g}$ load and dwell time of $15 \mathrm{~s}$ was adopted. The distance between two indentations was set to be $0.5 \mathrm{~mm}$.

\section{Results and Discussion}

\subsection{Microstructure}

A typical cross-sectioned macrostructure of a spot weld in DP600 steel is shown in Fig. 2. Microstructure profiles comparison of the weld joints at 8 and 17 cycles welding time is given in Fig. 3. Electrode force and welding time were set as $3.5 \mathrm{kN}$ and $10 \mathrm{kA}$ separately. As can be seen, fusion zone is mainly composed of columnar martensite as a consequence of high cooling rate in the cooling stage. Martensite size gets larger as welding time increases (Fig. 3: A0-A1), which indicated that the time of temperature stayed above $\mathrm{A}_{3}$ sustains longer for 17 cycles welding time. In addition, evenly distributed ferrite and martensite can be

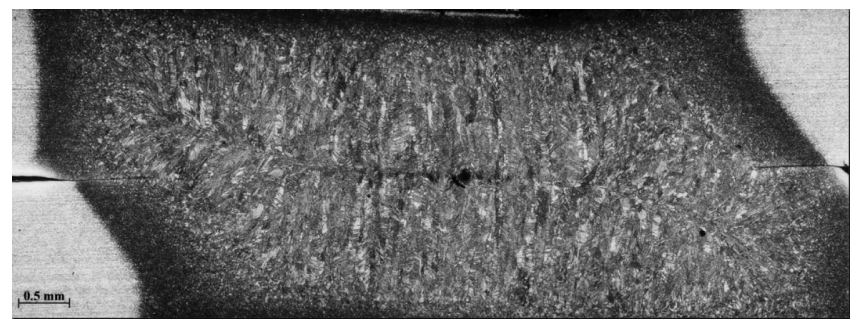

Fig. 2. A typical macrostructure of resistance spot weld.

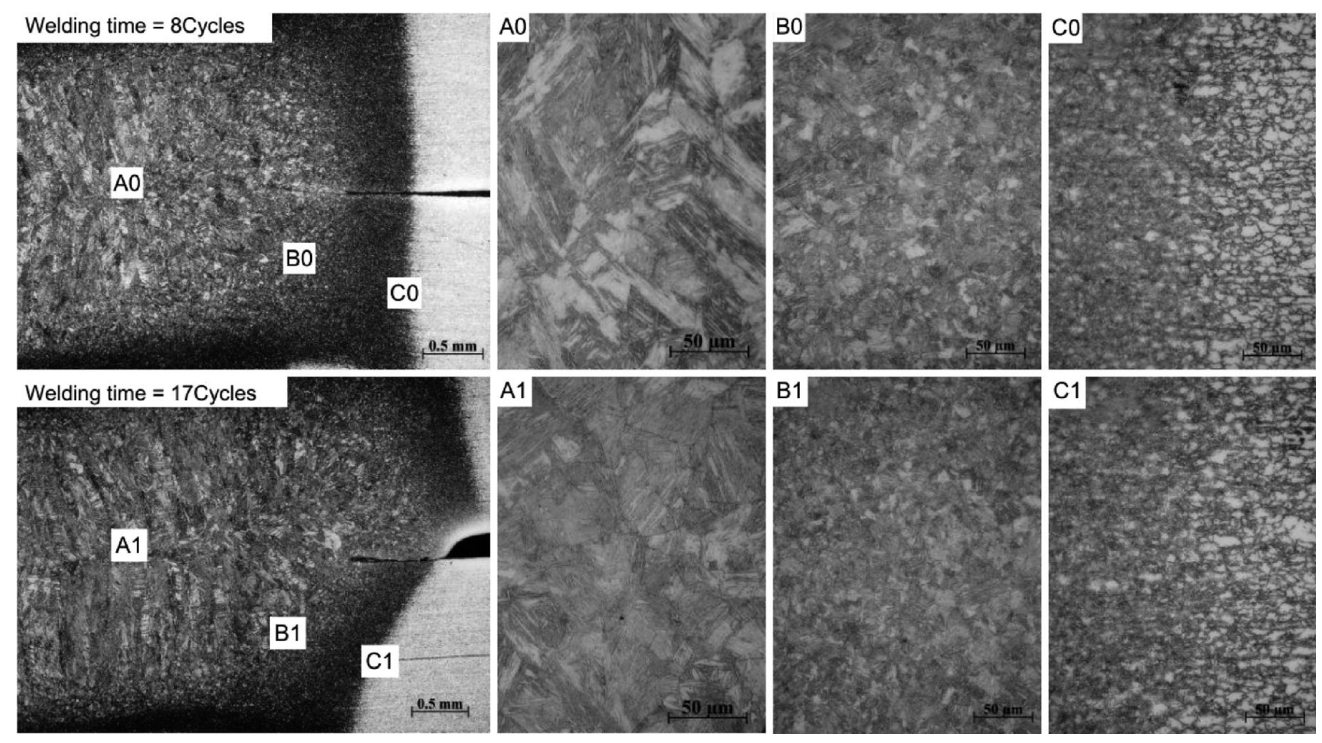

Fig. 3. Microstructure comparison with different welding time (electrode force $=3.5 \mathrm{kN}$, welding current $=10 \mathrm{kA}$ ). 
found in the HAZ and base metal.

\subsection{Microhardness}

The minimum, average and maximum vicker's microhardness values across the spot welds under different welding conditions are depicted in Fig. 4. Average hardness of weld nugget is found to be about $350 \mathrm{HV}$ due to the formation of hard martensite, which is much higher than the base metal hardness of $240 \mathrm{HV}$. HAZ softening is also observed, which can be explained by the martensite tempering at temperature below $\mathrm{A}_{1 .}{ }^{19)}$ Maximum hardness is generally mea-
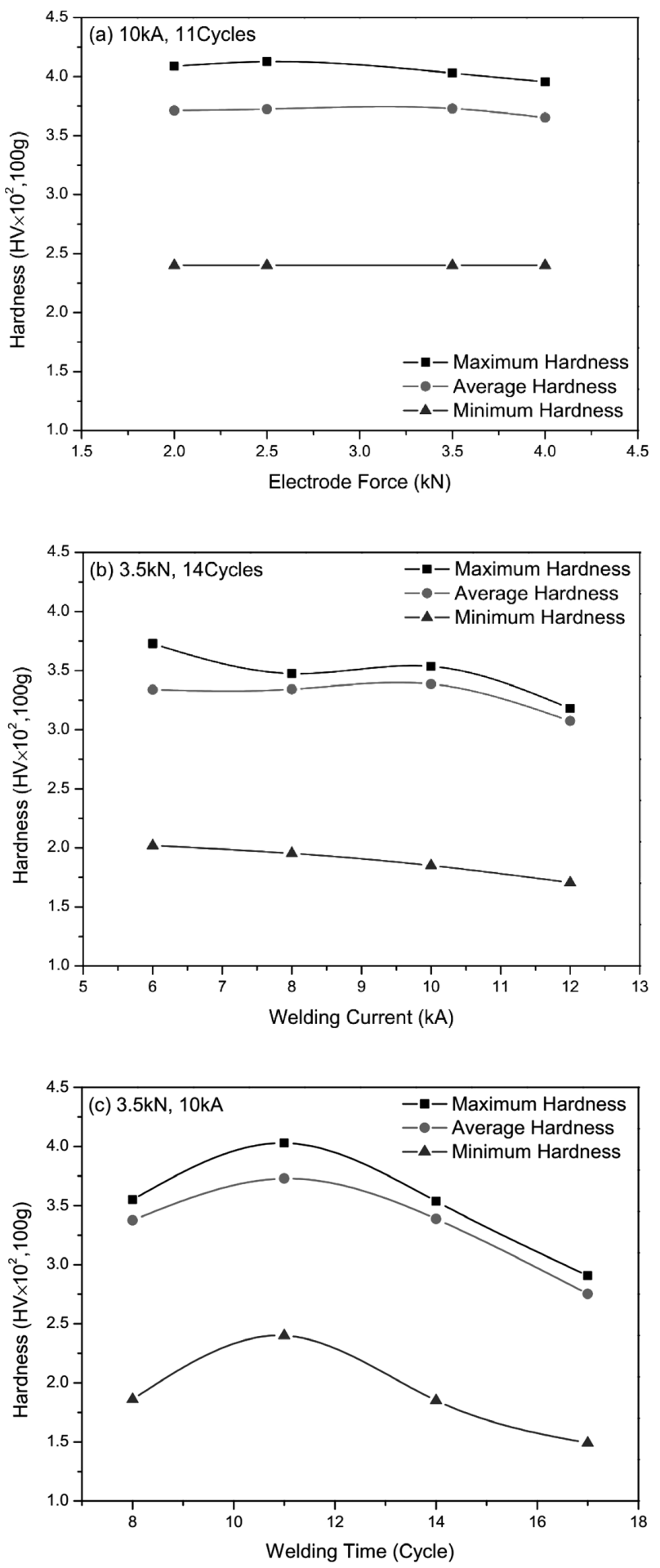

Fig. 4. Microhardness variation under different welding conditions. sured at the HAZ closing to fusion zone.

As it is shown in Fig. 4(a), the effect of electrode force on hardness value is almost negligible. No HAZ softening is found as electrode force increases. HAZ softening is obvious in Fig. 4(b) owing to the long welding time, which could be identified by the minimum hardness of $200 \mathrm{HV}$. All the measured hardness drops gradually as welding current gets higher in Fig. 4(b), which is caused by a sustained increase in grain size. Ductility of spot welds should be further improved meanwhile. Influence of welding time (Fig. 4(c)) on hardness is similar to that of welding current (Fig. 4(b)). All the minimum hardness values except for the 11 cycles welding time condition are softened. A similar downward trend of hardness can be observed in Fig. 4(c) as the welding time increases, which can also be attributed to the increase in grain size.

\subsection{Mechanical Properties}

Two typical failure modes are observed under tensileshear tests: interfacial failure (IF, Fig. 5(a)) and pullout failure (PF, Fig. 5(b)). A similar load versus displacement trend can be seen for these two failure modes before failure occurs, as shown in Fig. 6. IF occurs in a sudden way at

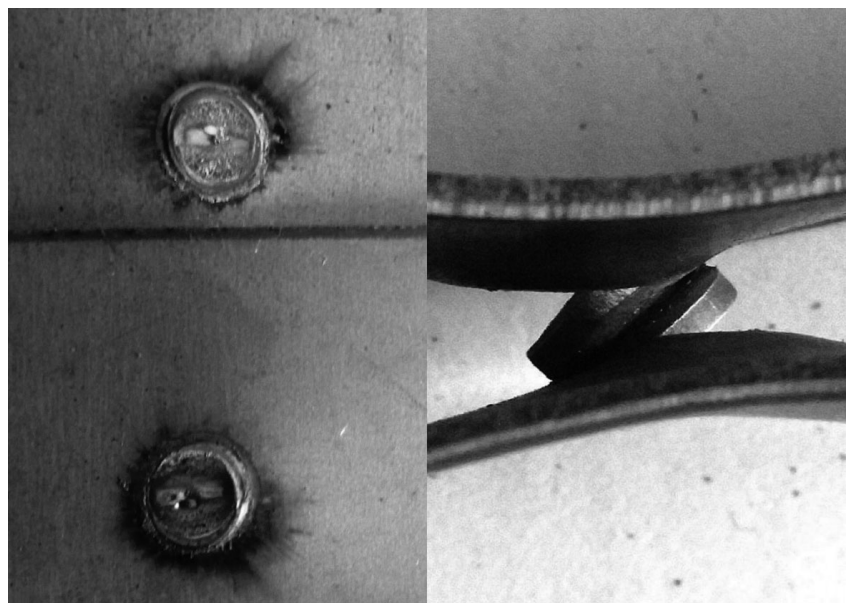

Fig. 5. Two typical failure modes (electrode force $=3.5 \mathrm{kN}$, welding current $=10 \mathrm{kA}$ ).

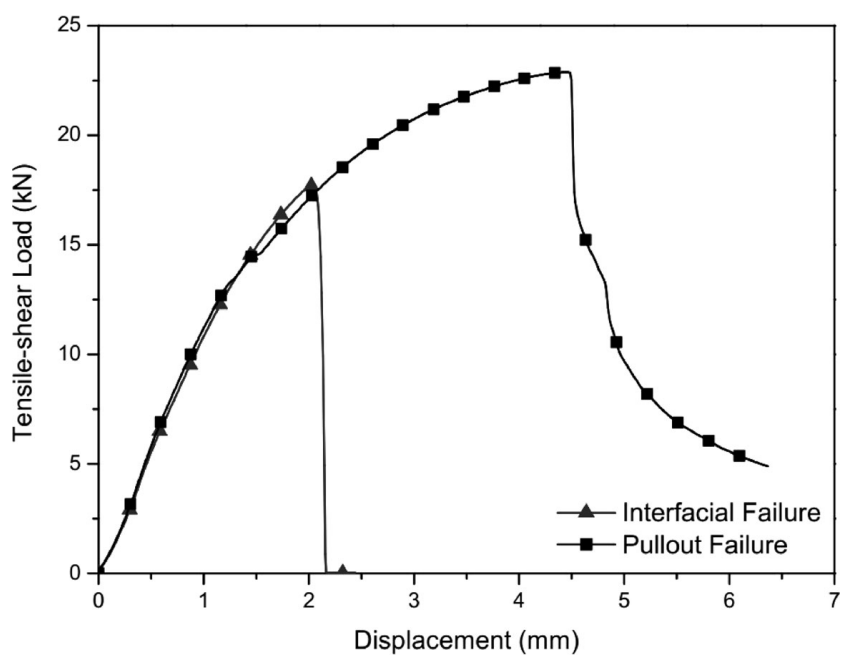

Fig. 6. Load-displacement curves. 
lower peak load. A "long tail" after peak load can be seen for $\mathrm{PF}$, which is caused by the failure's further expanding to base metal. Failure energy absorption in PF is much larger than in IF. Effects of electrode force, welding current and welding time on nugget size, tensile-shear peak load and failure energy absorption are given in Fig. 7. As can be seen, failure mode affects the mechanical properties of spot welds significantly, especially on failure energy absorption.

The influence of electrode force is shown in Fig. 7(a). Expulsion occurrence can be detected under $2.5 \mathrm{kN}$ welding condition. Heat input is reduced, and nugget size is unsatisfactory. When electrode force exceeds $3.5 \mathrm{kN}$, the increase in contact area further reduce the heat generation. A slightly
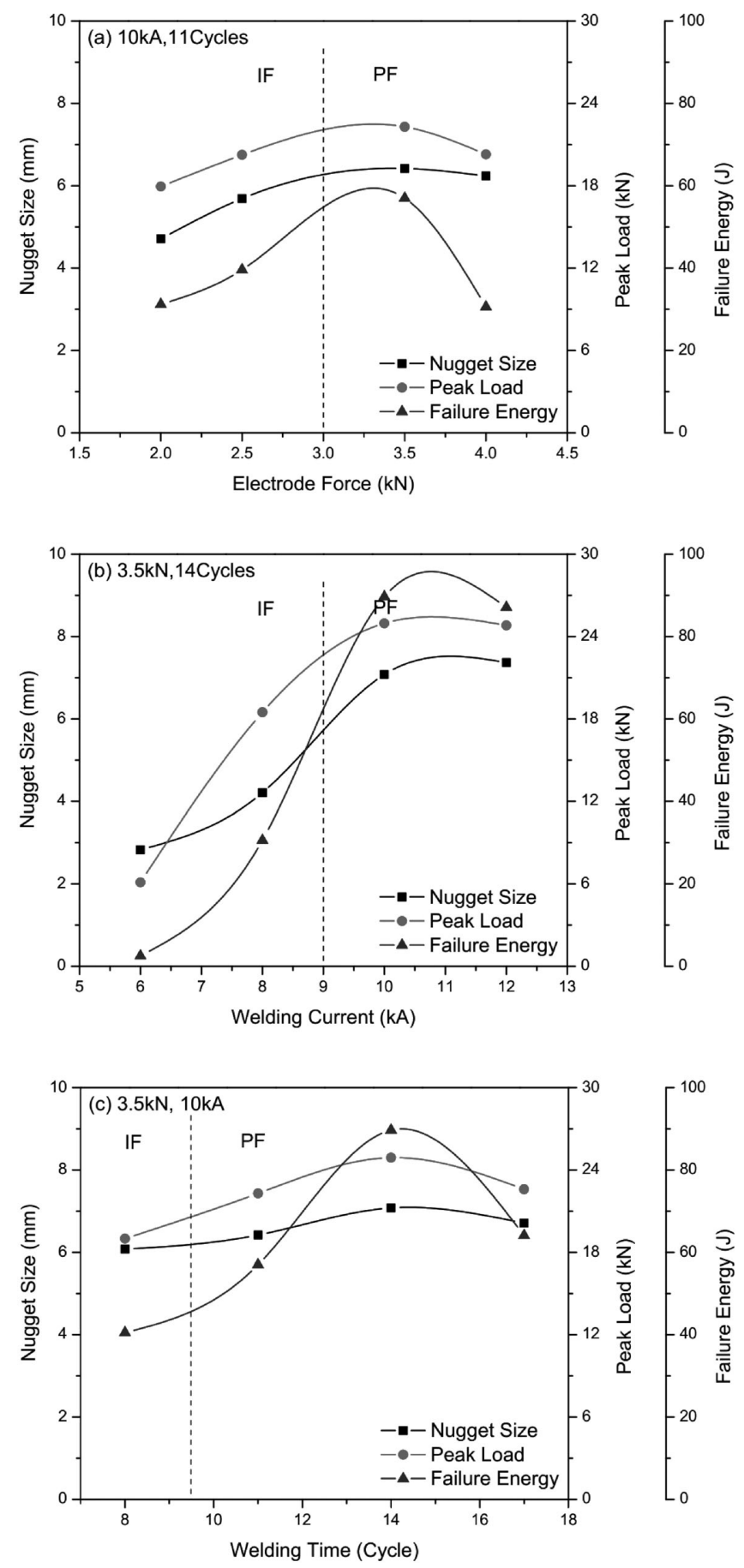

Fig. 7. Effects of welding parameters on weld quality (IF, interfacial failure; PF, pullout failure). downward trend of nugget size and peak load can then be observed under $4.0 \mathrm{kN}$ electrode force. However, the failure energy absorption drops dramatically at the same time. So the optimum electrode force can be selected as $3.5 \mathrm{kN}$ when welding current and welding time are kept constant at $10 \mathrm{kA}$ and 11 cycles separately.

The effect of welding current is depicted in Fig. 7(b). Welding current effect seems to be the most significant among the three selected welding parameters. This is due to heat generation is proportional to the square of welding current $\left(\mathrm{Q}=I^{2} R t\right)$. Peak load and failure energy absorption vary widely with welding current. Nugget size is enlarged and mechanical properties are strengthened consistently when welding current increases from $6 \mathrm{kA}$ to $10 \mathrm{kA}$. Expulsion occurs when welding current exceeds $10 \mathrm{kA}$, which decreases the failure energy absorption slightly. Thus it can be inferred that $10 \mathrm{kA}$ is the optimum welding current when the electrode force and welding time are kept constant at $3.5 \mathrm{kN}$ and 14 cycles separately.

Welding time effect on weld quality is given in Fig. 7(c), which is similar to that of electrode force. IF occurs only when welding time is 8 cycles. Although the peak load value at 14 cycles welding time is only $25 \%$ larger than that of 8 cycles, failure energy absorption difference can reach $100 \%$. Maximum failure energy absorption was obtained at 14 cycles welding time. Nugget size and failure performance drop as welding time increases from 14 cycles to 17 cycles, which may be due to the presence of welding defects like expulsion and shrinkage voids. Thus 14 cycles could be chosen as the optimum welding time when the electrode force and welding current are kept constant at $3.5 \mathrm{kN}$ and $10 \mathrm{kA}$. After comparing the aforementioned optimum welding parameters obtained, the $3.5 \mathrm{kN}$ elelctrode, $10 \mathrm{kA}$ welding current and 14 cycles welding time can be chosen as the final optimum welding schedules in this study.

\subsection{Penetration Rate}

Penetration rate of the weld nugget is also measured and depicted in Fig. 8. As can be seen, IF is usually accompanied by low penetration rate and small nugget size. When the penetration rate reaches $75 \%$ or more, $\mathrm{PF}$ makes up a majority. Penetration rate could probably be used to judge

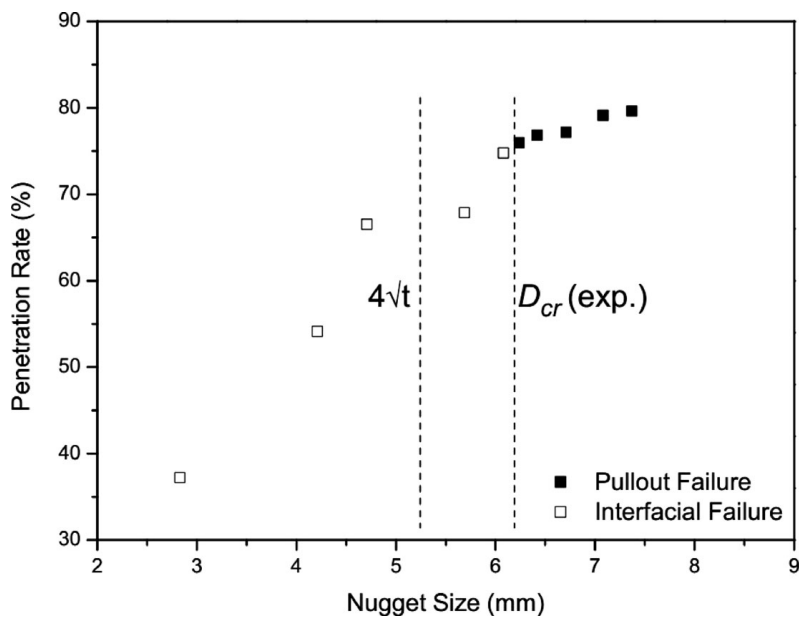

Fig. 8. Penetration rate variation with nugget size, $D_{c r}$ (exp.): experimentally determained critical nugget size. 
the weld quality in combination with the nugget size criterion.

What's more, the traditional failure mode criterion of $D_{c r}=4 \sqrt{t}^{20)}$ ( $t$, sheet thickness) is no longer suitable for DP600 spot welds. As seen in Fig. 8, IF still occurs while nugget size reaches $5.22 \mathrm{~mm}$. The critical nugget size suggested by Pouranvari as $D_{c r}=8 t H_{F L} / H_{W N}(t$, sheet thickness; $H_{F L}$, failure location hardness; $H_{W N}$, weld nugget hardness), however, is overestimated. ${ }^{21)}$ It is necessary to develop a new criterion considering HAZ softening and welding defects occurrence for a better prediction of failure mode. Further studies related to the failure prediction are in the plan.

\section{Conclusions}

In this study, effects of electrode force, welding current and welding time on resistance spot welding of DP600 steel were studied experimentally. Microstructure, micohardness and mechanical behavior were analyzed. Following conclusions can be obtained:

- HAZ softening due to martensite tempering is observed for spot welded DP600 steel sheets.

- Increasing welding parameters like electrode force, welding current and welding time promotes PF and HAZ softening.

- Welding defects like expulsion caused by low electrode force and long welding time have negative effects on weld quality.

- The effect of welding current on weld quality is more significant than either electrode force or welding time.

- Penetration rate could probably be used to judge the weld quality.

\section{Acknowledgements}

The authors are grateful to the National Natural Science
Foundation of China (Grant No. 11072083) for providing financial support. The sponsorship of the Fundamental Research Funds for the Central Universities, HUST: (Grant No. CXY13Q047) and the Graduates Innovation Fund of Huazhong University of Science \& Technology (Grant No. HF-11-14-2013) are also acknowledged.

\section{REFERENCES}

1) A. Fallahi: J. Mater. Sci. Technol., 18 (2002), 451.

2) M. I. Khan, M. L. Kuntz and Y. Zhou: Sci. Technol. Weld. Join., 13 (2008), 294.

3) M. Pouranvari and S. P. H. Marashi: Sci. Technol. Weld. Join., 15 (2010), 149.

4) P. K. Ghosh, P. C. Gupta, R. Avtar and B. K. Jha: ISIJ Int., 30 (1990), 233.

5) M. Milititsky, E. Pakalnins, C. Jiang and A. Thompson: SAE Tech. Paper, (2003).

6) C. Ma, D. L. Chen, S. D. Bhole, G. Boudreau, A. Lee and E. Biro: Mat. Sci. Eng. A, 485 (2008), 334.

7) M. Marya and X. Q. Gayden: Weld. J., 84 (2005), 172S.

8) M. Marya and X. Q. Gayden: Weld. J., 84 (2005), 197S.

9) M. Marya, K. Wang, L. G. Hector and X. H. Gayden: J. Manuf. Sci. Eng.-T. ASME, 128 (2006), 287.

10) A. Joaquin, A. N. A. Elliott and C. Jiang: Weld. J., 86 (2007), 24.

11) X. Zhang, G. Chen, Y. Zhang and X. Lai: J. Mater. Process. Technol., 209 (2009), 2671.

12) Y. Zhang, J. Shen and X. Lai: ISIJ Int., 52 (2012), 493.

13) V. H. B. Hernandez, M. L. Kuntz, M. I. Khan and Y. Zhou: Sci. Technol. Weld. Join., 13 (2008), 769.

14) M. Pouranvari and S. P. H. Marashi: Mater. Sci. Technol., 26 (2010), 1137.

15) M. Pouranvari, S. P. H. Marashi and D. S. Safanama: Mat. Sci. Eng. $A, \mathbf{5 2 8}$ (2011), 8344.

16) F. Nikoosohbat, S. Kheirandish, M. Goodarzi, M. Pouranvari and S. P. H. Marashi: Mater. Sci. Technol., 26 (2010), 738.

17) S. Dancette, V. Massardier-Jourdan, D. Fabregue, J. Merlin, T. Dupuy and M. Bouzekri: ISIJ Int., 51 (2011), 99.

18) E. Biro, S. Vignier, C. Kaczynski, J. R. Mcdermid, E. Lucas, J. D. Embury and Y. N. Zhou: ISIJ Int., 53 (2013), 110.

19) V. H. B. Hernandez, S. K. Panda, Y. Okita and N. Y. Zhou: J. Mater. Sci., 45 (2010), 1638.

20) Recommended Practices for Test Methods for Evaluating the Resistance Spot Welding Behavior of Automotive Sheet Steel Materials, ANSI/AWS D8. 9-97, American Welding Society, Miami, (1997).

21) M. Pouranvari, H. R. Asgari, S. M. Mosavizadch, P. H. Marashi and M. Goodarzi: Sci. Technol. Weld. Join., 12 (2007), 217. 